\title{
Epidemics and Yield Losses due to Corynespora cassiicola on Cotton
}

Kira L. Bowen ${ }^{\dagger}$ and Austin K. Hagan, Department of Entomology and Plant Pathology; Malcolm Pegues, Jarrod Jones, Gulf Coast Research and Extension Center; and H. Brad Miller, Brewton Agricultural Research Unit, Auburn University, AL 36849

\begin{abstract}
Target spot, caused by Corynespora cassiicola, has recently emerged as a problematic foliar disease of cotton. This pathogen causes premature defoliation during boll set and maturation that can subsequently impact yield, and on certain cotton cultivars loss can be substantial. This study sought to better understand target spot epidemics and disease-incited yield losses on cotton. In order to establish a range of disease, varying numbers of fungicide applications were made to each of two cotton cultivars in each of four site-years. Target spot intensity was rated over several dates beginning in late July or early August and continuing into September. Yield of seed plus lint (seed cotton) was recorded at harvest. When analyzed across cultivars, a second or third fungicide application increased yield compared with no treatment.

Lack of significant yield response with a single fungicide application may have been due to timing of that application which preceded disease onset. The cultivar PhytoGen 499 WRF had consistently greater defoliation than any of the three Deltapine cultivars grown in each site-year. However, yields of both cultivars responded similarly to the fungicide regimes. Yield loss models based on late August defoliation were only predictive at site-years where conditions favored target spot development, i.e., abundant rain and moderate temperatures. Epidemic development fit the Gompertz growth model better than it did a logistic model. Knowledge of the underlying mathematical character of the epidemiology of target spot will prove useful for development of a predictive model for the disease.
\end{abstract}

Corynespora cassiicola (Berk. \& M.A. Curtis) C.T. Wei is a cosmopolitan fungal plant pathogen that frequently causes leaf spots and premature defoliation of its hosts. Diseases incited by this pathogen cause yield losses on several crops, e.g., cowpea (Rodriguez and Melendez 1984), cucumber (Blazquez 1967), rubber (Fernando et al. 2010; Jayasinghe 2000), and tomato (Pernezny et al. 2002). Fungicide treatments are frequently used to manage Corynespora-incited diseases and improve yields.

In recent years, $C$. cassiicola has been increasing in prevalence on soybean (Glycine max) (Koenning et al. 2006) and on cotton (Gossypium hirsutum), especially in the Southeast and South Central United States (Butler et al. 2016; Conner et al. 2013; Fulmer et al. 2012; Price et al. 2015; Schultz 2017). This pathogen has also been recently reported on cotton in Brazil (Galbieri et al. 2014) and in China (Wei et al. 2014). C. cassiicola infection causes lesions on cotton foliage that appear as concentric light and dark brown rings; thus, this disease on cotton is called "target spot." Spots are initially found in the lower, interior canopy and spread upward. Premature defoliation of symptomatic leaves follows.

In a study done in southwestern AL, U.S., lint yield loss due to target spot on an apparently susceptible cotton cultivar had been estimated as high as $448 \mathrm{~kg}$ lint/ha (Hagan et al. 2015b). This loss estimate was based on yield from non-fungicide-treated plots compared with full-season fungicide-treated cotton. A recent analysis from a common experiment conducted at 16 site-years found that a single fungicide application at target spot onset would provide a 4 to $6 \%$ yield gain compared with no treatment (Mehl et al. 2017). Mehl et al. (2017) also noted reduced defoliation due to target spot and a further improvement of yields with two versus a single fungicide application. Cotton yields currently average $958 \mathrm{~kg}$ lint/ha in the

${ }^{\dagger}$ Corresponding author: K. L. Bowen; E-mail: bowenkl@auburn.edu

Funding: Funding for this project was provided by the Alabama Agricultural Experiment Station, grants from USDA National Institute of Food and Agriculture (USDA NIFA) Crop Pest and Pest Management Program (award number 2014-70006-22515), the Alabama Cotton Commission, and a cooperative research agreement with Cotton Incorporated (Impact and Management of Target Spot).

Accepted for publication 21 May 2018.

() 2018 The American Phytopathological Society
United States (NASS 2017); thus, a $4 \%$ yield gain from a single fungicide application would be about $38 \mathrm{~kg}$ lint/ha. Depending on lint price and cotton cultivar, multiple fungicide applications might be justified for managing target spot.

Target spot damage and yield losses can be highly variable (Mehl et al. 2017). Cultivar differences, canopy closure timing, and weather, including microclimate effects, can substantially impact target spot development. Growers could benefit from implementation of a forecast or disease advisory system for target spot on cotton to facilitate efficient and cost-effective fungicide use when weather is conducive for disease development. Conditions that are favorable for target spot development appear to be long periods of leaf wetness and moderate temperatures based on growth chamber studies (Sharma 2017). In order to develop an effective advisory for target spot, epidemic development must first be understood. This study sought not only to characterize epidemics of target spot on cotton, but also to quantify yield losses due to premature defoliation caused by the disease.

\section{Materials and Methods}

Experimental design. This study was initiated in 2012 at the Gulf Coast Research and Extension Center (GCREC; 30.5461, -87.8801) in Fairhope, AL, and was repeated in 2013 and 2016. A second study site, the Brewton Agricultural Research Unit (BARU; 31.1409, -87.0489) in Brewton, AL, was added in 2016. Field plots consisted of a factorial set of treatments arranged in a split-plot design with cotton cultivar as the main plot and fungicide treatments as subplots. Individual subplots consisted of four $7.6 \mathrm{~m}$ rows spaced $0.9 \mathrm{~m}$ apart; there were four blocks of treatments. Two cultivars were: PhytoGen 499 WRF and a Deltapine cultivar (DP) which included DP 1050 B2RF in 2012, DP 1252 B2RF in 2013, and DP 1137 B2RF in 2016. Based on observations made in other studies, PhytoGen 499 WRF is susceptible to target spot, while the DP cultivars are partially resistant (e.g., Hagan et al. 2013; Hagan et al. 2015a). Target spot disease reactions and yields are similar across these DP cultivars (Hagan et al. 2013).

Headline 2.09SC (pyraclostrobin, a quinone-outside inhibitor fungicide with locally systemic mobility; BASF Corp, Research Triangle Park, NC) was applied at $877 \mathrm{ml} / \mathrm{ha}$, and different numbers of applications $(0,1,2,3,4$, or 5$)$ were used to establish varying levels of disease. Applications began at first bloom in 2012 and 2013, and at pin-head square in 2016, with subsequent applications planned for 14-day intervals (details in Table 1).

Crop management. Cotton growth, weeds, and insect pests were managed as recommended for the region (Reed et al. 2017). Stink 
bugs (Euchistus sp. and Nezaria sp.) were a problem at both sites in 2016 and were controlled with an application Bidrin XP II (at $584 \mathrm{ml} / \mathrm{ha}$; dicrotophos, AMVAC Chemical Corp., Los Angeles, CA). Cotton was prepared for harvest with defoliants as recommended (Reed et al. 2017) and mechanically harvested; bulk seed weight of each plot was recorded at harvest. Seed weight, as used herein, is comprised of cotton lint and cottonseed that are harvested in bulk. Ginned lint, after cottonseed removal, is generally about $40 \%$ of the total seed weight.

Disease assessment. Target spot intensity assessments began in late July, 3rd to 4th week of bloom, and continued on approximately 2 -week intervals into September (Table 1). Disease intensity was rated using a 1 to 10 leaf spot scoring system (Chiteka et al. 1988) where: $1=$ no disease, 2 = very few lesions in canopy, $3=$ few lesions noticed in lower and upper canopy, $4=$ some lesions seen and $\leq 10 \%$ defoliation, $5=$ lesions noticeable and $\leq 25 \%$ defoliation, $6=$ lesions numerous and $\leq 50 \%$ defoliation, $7=$ lesions very numerous and $\leq 75 \%$ defoliation, $8=$ numerous lesions on few remaining leaves and $\leq 90 \%$ defoliation, $9=$ very few remaining leaves covered with lesions and $\leq 95 \%$ defoliation, and $10=$ plants completely defoliated. In each plot, three groups of multiple plants were visually examined in order to assign a score that represented the entire plot. Percent disease severity was calculated using the formula [\% severity $=100 /(1+$ $e$ (-(disease intensity score - 6.0672)/0.7975)] (modified from Li et al. 2012). This calculation provides a $\%$ severity that considers both $\%$ defoliation and density of lesions on remaining leaves.

Data analysis. Areas under disease progress curves (AUDPCs) were calculated (Shaner and Finney 1977) from \% severity values for each plot in each site-year. AUDPCs were divided by the number of days over which observations were made in each site-year (45 in
2012, 72 in 2013, and 43 and 66 for GCREC and BARU in 2016, respectively) to generate relative AUDPCs (rAUCs) to compare across site-years. Generalized linear mixed model analyses using PROC GLIMMIX (SAS 9.4, SAS Institute, Cary, NC) were done on \% severity noted for the late August assessment date, rAUCs, and seed + lint yields (kg/ha) (hereafter referred to as seed cotton yields). Cotton cultivar, numbers of fungicide applications, and the 2-way interaction of these terms were fixed effects in the model; site-year, block within siteyear, and block $\times$ cultivar within site-year were random effects. The late August assessments for disease were evaluated as these dates provided more consistency relative to plant development stage across siteyears. Means were separated with Fisher's protected least significant difference with $P<0.05$. Differences between single factor effects were tested using the SLICEDIFF option and single degree of freedom comparisons in PROC GLIMMIX. While these analyses were done on pooled data over all site-years, there were substantial differences in disease development and yields between site-years. 'Site-year' as a fixed factor in mixed model analysis significantly impacted rAUC and yield $(P<0.0001)$. Because of this, disease development and yield loss models were calculated for each site-year, rather than over pooled data.

Modeling yield loss. The effect of disease on yield was evaluated by regressing seed cotton yield on late August severity estimates for each cultivar in each site-year. Linear and quadratic models were calculated. For significant models, fit was evaluated by examining coefficients of determination $\left(R^{2}\right)$, patterns of the residuals, and root-square mean errors (RSME).

Modeling epidemic development. Disease severity (\%) values from nontreated plots for all dates were transformed using linearizations for logistic $(\ln (x /(1-x)))$ and Gompertz $(-\ln (-\ln (x)))$ disease

Table 1. Production details of cotton yield loss study

\begin{tabular}{cccllcc}
\hline Year & Site & Planting date & Fungicide application dates & Disease assessment dates & Harvest date & Average defoliation $^{\mathbf{x}}$ \\
\hline 2012 & GCREC & $5 / 9$ & $7 / 5,7 / 23,8 / 7,8 / 22,9 / 4$ & $7 / 31,8 / 13,8 / 27,9 / 7,9 / 13$ & 11 Oct & 84.9 \\
2013 & GCREC & $5 / 9$ & $7 / 10,7 / 31,8 / 12,8 / 27$ & $7 / 29,8 / 14,8 / 26,9 / 9$ & 14 Oct & 67.5 \\
2016 & GCREC $^{2}$ & $5 / 9$ & $6 / 28,7 / 5,7 / 18,8 / 1,8 / 17$ & $7 / 20,8 / 1,8 / 15,8 / 31$ & 28 Sept & 75.2 \\
& BARU $^{z}$ & $5 / 5$ & $7 / 6,7 / 19,8 / 2,8 / 16$ & $8 / 2,8 / 16,8 / 24,9 / 8,9 / 14,9 / 23$ & 25 Oct & 59.0 \\
\hline
\end{tabular}

${ }^{x}$ Average \% defoliation on nontreated PhytoGen 499 on final assessment date.

y GCREC $=$ Gulf Coast Research and Extension Center in Fairhope, AL (30.5461, -87.8801)

${ }^{\mathrm{z}}$ BARU $=$ Brewton Agricultural Research Unit in Brewton, AL (31.1409, -87.0489).
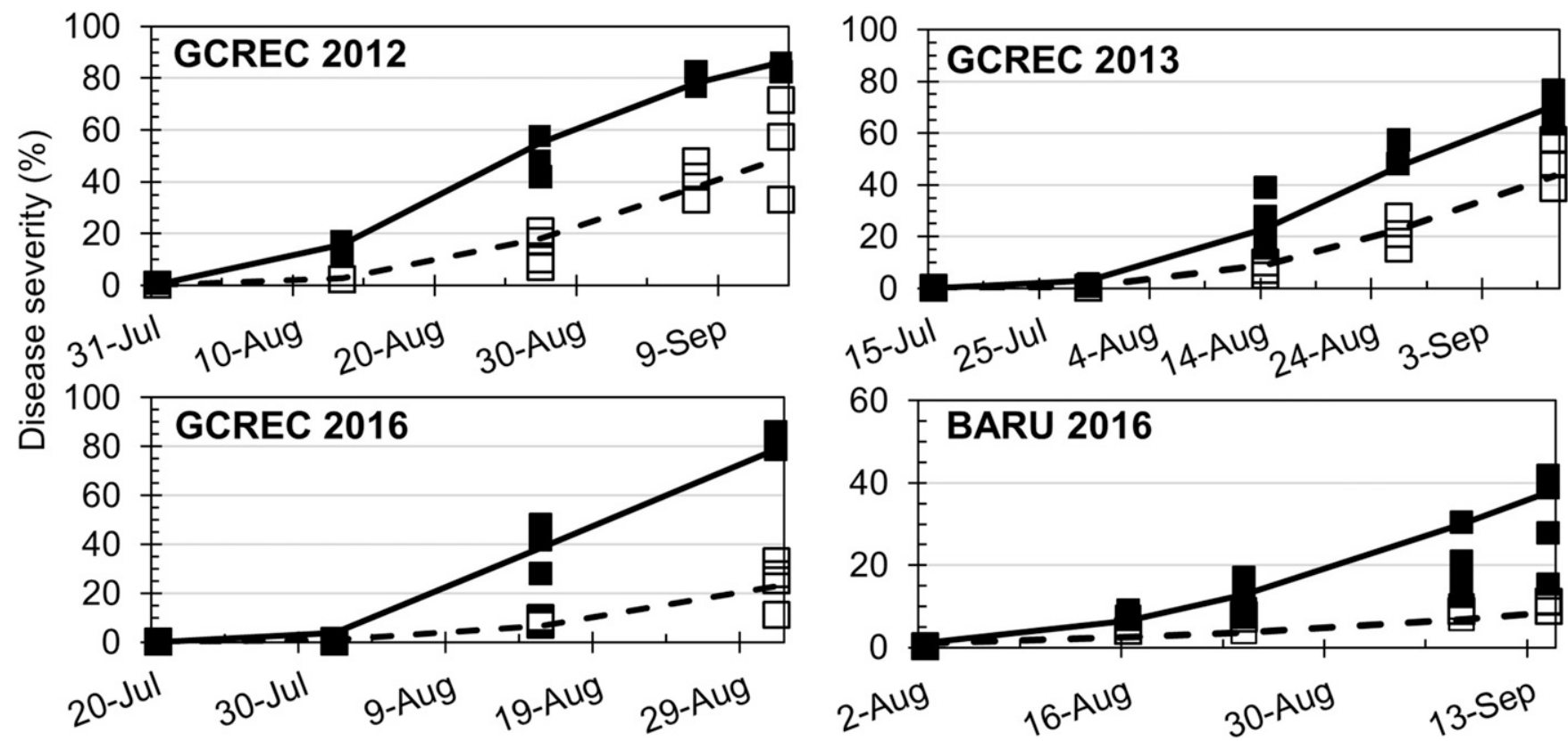

Fig. 1. Target spot disease severity (\%) over time on each of two cotton cultivars without fungicide treatment at four site-years. Each marker represents a field observation from a single replication; lines represent Gompertz model predictions of disease development. Solid markers and lines illustrate disease on PhytoGen 499 WRF; open markers and dashed lines show disease on Deltapine (DP) cultivars (DP 1050 B2RF, DP 1252 B2RF, and DP 1137 B2RF in 2012, 2013, and 2016, respectively). GCREC is the Gulf Coast Research and Extension Center in Fairhope, AL, and BARU is Brewton Agricultural Research Unit, in Brewton, AL. 
progress models (Campbell and Madden 1990), where $x$ is \% severity. Transformed data were regressed on days with 1 July = day 1 (e.g., 15 July was day 15,8 Aug was day 39 ) for each cultivar in each site-year. Intercepts and coefficients of each of the resultant models were compared using $F$ tests $(P \leq 0.05)$.

Weather. Daily temperature (minimum and maximum) and rainfall amounts were recorded by and collected from AL Mesonet stations in each site-year. Plots were located within $305 \mathrm{~m}$ of the weather station at GCREC and $460 \mathrm{~m}$ at BARU.

\section{Results}

Factor effects. In all site-years, target spot became noticeable (i.e., greater than $1 \%$ severity) on nontreated plots in early August (Fig. 1). Target spot intensity increased rapidly through August in the 3 years at GCREC, reaching $\geq 70 \%$ disease severity on PhytoGen 499 WRF and $>40 \%$ on the DP cultivars. Single degree of freedom comparisons between site-years showed that late August defoliation in 2012, 2013, and 2016 at GCREC was similar on the DP cultivars in nontreated plots $(P>0.25)$; in 2016 at BARU, target spot on the DP cultivar was lower than in any of the other site-years (Fig. $1 ; P<$ $0.0001)$. The DP cultivars consistently had lower levels of disease than PhytoGen 499 WRF in each site-year (Fig. 1). Analysis over all site-years confirmed that DP cultivars had significantly lower $(P<0.0001)$ disease severity in late August and rAUC than did PhytoGen 499 WRF (Table 2). Fungicide application number also had significant effects $(P<0.0001)$ on late August disease and rAUC, but the 2-way interactions of cultivar and application number were not significant for either variable. Analyzed across both cultivars in all site-years, one or two fungicide applications reduced target spot compared with no fungicide, and further reduction in disease severity was seen with three or more fungicide applications (Table 2). In addition, rAUC values were lower with three or more, compared with two fungicide applications, which was better than a single fungicide application for reducing rAUC; one fungicide application significantly reduced rAUC compared with the no fungicide control.

Single degree of freedom comparisons showed that, over the four site-years, nontreated PhytoGen 499 WRF had significantly higher

Table 2. Significance levels ( $P$ values) from generalized linear mixed model analyses of the effect of cultivar and fungicide applications on target spot and cotton yield over four site-years in southern AL

\begin{tabular}{lccc}
\hline & Late August disease severity & rAUC & $\begin{array}{c}\text { Seed yield } \\
(\mathbf{k g} / \mathbf{h a})\end{array}$ \\
\hline Cultivar $^{\text {No. applications }}$ & $<0.0001$ & $<0.0001$ & 0.9930 \\
2-way interaction & $<0.0001$ & $<0.0001$ & $<0.0001$ \\
Cultivar & 0.7542 & 0.7235 & 0.0291 \\
$\quad$ DPs $^{\mathrm{w}}$ & & & \\
P499 & $1.3^{\mathrm{x}} \mathrm{b}^{\mathrm{v}}$ & $7.24^{\mathrm{x}} \mathrm{b}^{\mathrm{v}}$ & $3650.1^{\mathrm{x}} \mathrm{a}^{\mathrm{y}}$ \\
No. of fungicide & $22.6 \mathrm{a}$ & $15.61 \mathrm{a}$ & $3649.5 \mathrm{a}$ \\
$\quad$ & & & \\
$\quad$ applications & & & \\
0 & $34.0 \mathrm{a}$ & $22.16 \mathrm{a}$ & $3410.5 \mathrm{c}$ \\
1 & $24.0 \mathrm{~b}$ & $15.02 \mathrm{~b}$ & $3476.2 \mathrm{bc}$ \\
2 & $17.0 \mathrm{~b}$ & $11.25 \mathrm{c}$ & $3584.3 \mathrm{~b}$ \\
3 & $9.6 \mathrm{c}$ & $8.05 \mathrm{~d}$ & $3800.1 \mathrm{a}$ \\
4 & $10.3 \mathrm{c}$ & $7.15 \mathrm{~d}$ & $3763.4 \mathrm{a}$ \\
$5^{\mathrm{z}}$ & $3.7 \mathrm{~d}$ & $4.94 \mathrm{e}$ & $3860.6 \mathrm{a}$ \\
\hline
\end{tabular}

u rAUC is 'relative Area Under Disease Progress Curve' which is AUDPC divided by the duration, in days for each site-year, over which disease was monitored.

$\checkmark$ Applications are numbers of fungicide applications (0 to 5); fungicide was Headline at $877 \mathrm{ml} / \mathrm{ha}$.

${ }^{\text {w }}$ Deltapine cultivars differed between years: DP 1050 B2RF in 2012, DP 1252 B2RF in 2013, and DP 1137 B2RF in 2016; P499 cultivar is PhytoGen 499 WRF.

${ }^{x}$ Data are means over four site-years and four replications in each site-year.

${ }^{y}$ Letters following numbers, when different, indicate significant differences according to Fisher's protected LSD at $P<0.05$.

z Only two of the four studies (GCREC in 2012 and 2016) included the fifth application. target spot severity than did nontreated DP cultivars $(45.8 \%$ and $22.1 \%$, respectively; $P=0.006$ ) in late August. The single fungicide application reduced disease severity of PhytoGen 499 WRF to 35\%, which was not statistically different from the late August disease observed on the nontreated DP cultivars $(P=0.32)$.

Over four site-years, yield differences were significant $(P<$ 0.0001 ) due to numbers of fungicide applications, but not cultivar (Table 2); however, the 2-way interaction of these factors was significant $(P=0.029)$. Compared with no fungicide application, two fungicide applications did not significantly improve seed yield of DP cultivars, but did improve yield of PhytoGen 499 WRF (Fig. 2); this differential effect in cultivar response likely led to the significance of the 2-way interaction. Seed cotton yield gain with two fungicide applications compared with no fungicide was $3.2 \%$ and $7.2 \%$ for DP cultivars and PhytoGen 499 WRF, respectively. Single degree of freedom comparisons of PhytoGen 499 WRF to DP cultivars indicated statistically similar yields for each fungicide regime. However, when late August disease severity of PhytoGen 499 WRF was low (in this study with 4 and 5 fungicide applications and with all treatments at BARU 2016), this cultivar out-yielded all treatments on DP 1050 B2RF (GCREC 2012) and DP 1137 B2RF (both locations in 2016) by 3 to $6 \%$ ( 84 to 224 seed $\mathrm{kg} / \mathrm{ha}$ ).

Target spot severity effects on yield. Linear regression of late August disease severity on seed cotton yield for each of the cultivars in each site-year provided a better fit for the data than did the quadratic model based on patterns of residuals, coefficients of determination and model significance. All models derived for PhytoGen 499 WRF were significant $(P<0.07)$ (Table 3); of these the 2012 and 2013 models had $R^{2}>0.50$ indicating that late August disease levels explain about half of the variability in yields from plots. Intercepts of models, which indicate yield potential in each site-year, ranged from 3,385 to $4,332 \mathrm{~kg} / \mathrm{ha}$ seed cotton for PhytoGen 499 WRF. Since intercepts differed significantly among site-years, the data were not pooled for calculation of a single model across environments (Fig. 3). Coefficients of the disease variable (= slope) of these models (Table 3) ranged from -32.6 to -5.1 , indicating the amount of seed loss with each (\%) unit increase in disease severity. The percent loss calculated for PhytoGen 499 WRF with $10 \%$ disease severity was approximately 4\% using the significant 2012 and 2013 models. Models for the DP cultivars, except in 2013, were not significant; the 2013 DP cultivar model had an $R^{2}=0.26$, indicating a relatively poor prediction of yield from late August defoliation. In several instances, yield loss models were not significant or provided poor fit to the data due to highly variable cotton seed yields, as with PhytoGen $499 \mathrm{WRF}$ at GCREC in 2016, or a limited range of values for disease severity, e.g., only up to $16 \%$ on both cultivars at BARU in 2016 (Fig. 3).

Target spot development. Disease development over time in each site-year and for each cultivar fit both the logistic $\left(R^{2} \geq 0.65, P<\right.$ $0.0001, \mathrm{RSME}<0.94)$ and the Gompertz $\left(R^{2}>0.74, P<0.0001\right.$, RSME < 0.41) growth models. RSMEs were consistently lower with

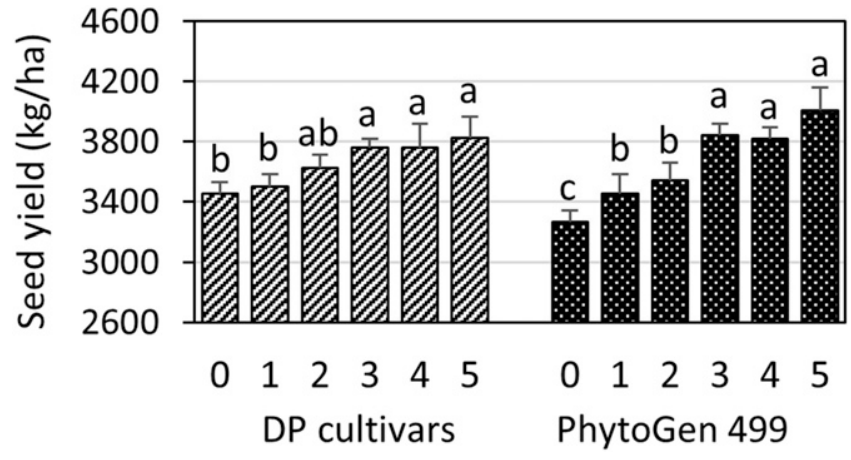

Fig. 2. Seed + lint cotton yield $(\mathrm{kg} / \mathrm{ha}$ ) for two cultivars and with 0 to 5 fungicide applications. Data are means of four replications over 4 site-years. Letters on bars, when different, indicate significant differences $(P<0.05)$ within each cultivar according to Fisher's protected least significance differences. Error bars represent standard error of the means. 
Gompertz models, indicating a lower standard deviation between actual observations and predicted values. The slopes of the models, which reflect the apparent infection rate of the epidemics, were consistently lower for the DP cultivars than for PhytoGen 499 WRF in each site-year (Table 4, Fig. 1), indicating slower epidemic development on the former cultivars. Among site-years, slope was lowest for the BARU 2016 epidemics. Solving each of the models for the date of noticeable target spot (or "onset" at $1 \%$ disease severity) confirmed that target spot became conspicuous in late July to early August (Table 4).

Effects of weather. Because target spot lesions were first observed in late July to early August, weather was examined from 15 July to 31 August. Average temperature over these 47 days differed by only $1{ }^{\circ} \mathrm{C}$ among site-years. However, $>33 \mathrm{~cm}$ rain was recorded over this period in 2012 and 2013, while $<20 \mathrm{~cm}$ was measured at both sites in 2016 (Fig. 4). While the total rainfall amount at GCREC in 2016 was low, there was a rain event generally every 3 days, and this favored target spot development. At BARU in 2016, target spot did not increase rapidly through August, and in addition to low rainfall in this site-year, there were 39 days with maximum temperatures $>32^{\circ} \mathrm{C}$ compared with 34,27 , and 25 days exceeding $32^{\circ} \mathrm{C}$ at the 2012, 2013, and GCREC 2016 site-years, respectively (Fig. 4).

\section{Discussion}

In order to quantify yield losses due to plant disease, a range of levels of disease damage must be established (Madden et al. 2007). In this study, varying numbers of fungicide applications were used to establish different target spot levels on two cotton cultivars. A single fungicide application at early flowering stages reduced average premature defoliation and lesion numbers due to target spot compared with no fungicide; the second application reduced disease further, especially as measured by rAUC. These results are comparable to observations by Mehl et al. (2017), who noted that two fungicide applications reduced defoliation due to target spot compared with one or no fungicide applications. However, multiple fungicide applications may not be as critical as application timing. Mehl et al. (2017) noted 4 to $6 \%$ and 7 to $8 \%$ yield gains with one and two fungicide applications, respectively, compared with no fungicide. In the current study, yield gains were lower, averaging 2 and 5\%, respectively, with one and two fungicide applications. Larger yield gains noted by Mehl et al. (2017) could be because their first fungicide application was closer to disease onset, while in the current study the first fungicide application was done 2 to 4 weeks prior to disease onset. Fungicide applications, beginning when lesions were first seen, have also been shown to reduce Alternaria-incited premature defoliation of cotton and to improve seed yield by as much at 22\% (Bashi et al. 1983).

Strobilurin fungicides, such as pyraclostrobin as used in this study, are known to improve plant growth and yields of healthy plants (Kanungo and Joshi 2014). Strobilurins effectively prolong photosynthetic processes and retard leaf senescence, and this allows for increased grain fill. While pyraclostrobin did not consistently increase cotton growth or yield in studies done by Woodward et al. (2016), it

Table 3. Results of regression of yield on late August defoliation. Linear model parameter values and fit statistics.

\begin{tabular}{llcccrc}
\hline Cultivar & Year-site & Intercept & Coefficient & $\boldsymbol{R}$-squared & $\boldsymbol{P}$ value & Estimated \% loss $^{\mathbf{x}}$ \\
\hline DPy 1050 & 2012 - GCREC & 3992.0 & -9.86 & 0.042 & 0.2969 & 2.47 \\
DP 1252 & 2013 - GCREC & 4064.4 & -23.56 & 0.259 & 0.0056 & 5.80 \\
DP 1137 & 2016 - GCREC & 3289.4 & -1.22 & 0.004 & 0.7579 & 0.37 \\
DP 1137 & 2016 - BARU & 3579.8 & 0.95 & 0.0003 & 0.9323 & -0.26 \\
PhytoGen 499 & 2012 - GCREC & 4331.9 & -17.08 & 0.513 & $<0.0001$ & 3.94 \\
& 2013 - GCREC & 3913.0 & -14.86 & 0.538 & $<0.0001$ & 0.0650 \\
& 2016 - GCREC & 3385.4 & -5.12 & 0.125 & 0.0425 & 1.51 \\
& 2016 - BARU & 4036.1 & -32.65 & 0.149 & & 8.09 \\
\hline
\end{tabular}

${ }^{\mathrm{x}}$ Loss is estimated for $10 \%$ disease severity.

${ }^{y} \mathrm{DP}=$ Deltapine.

${ }^{\mathrm{z}}$ Site acronyms are: GCREC $=$ Gulf Coast Research and Extension Center in Fairhope, AL; BARU = Brewton Agricultural Research Unit in Brewton, AL.
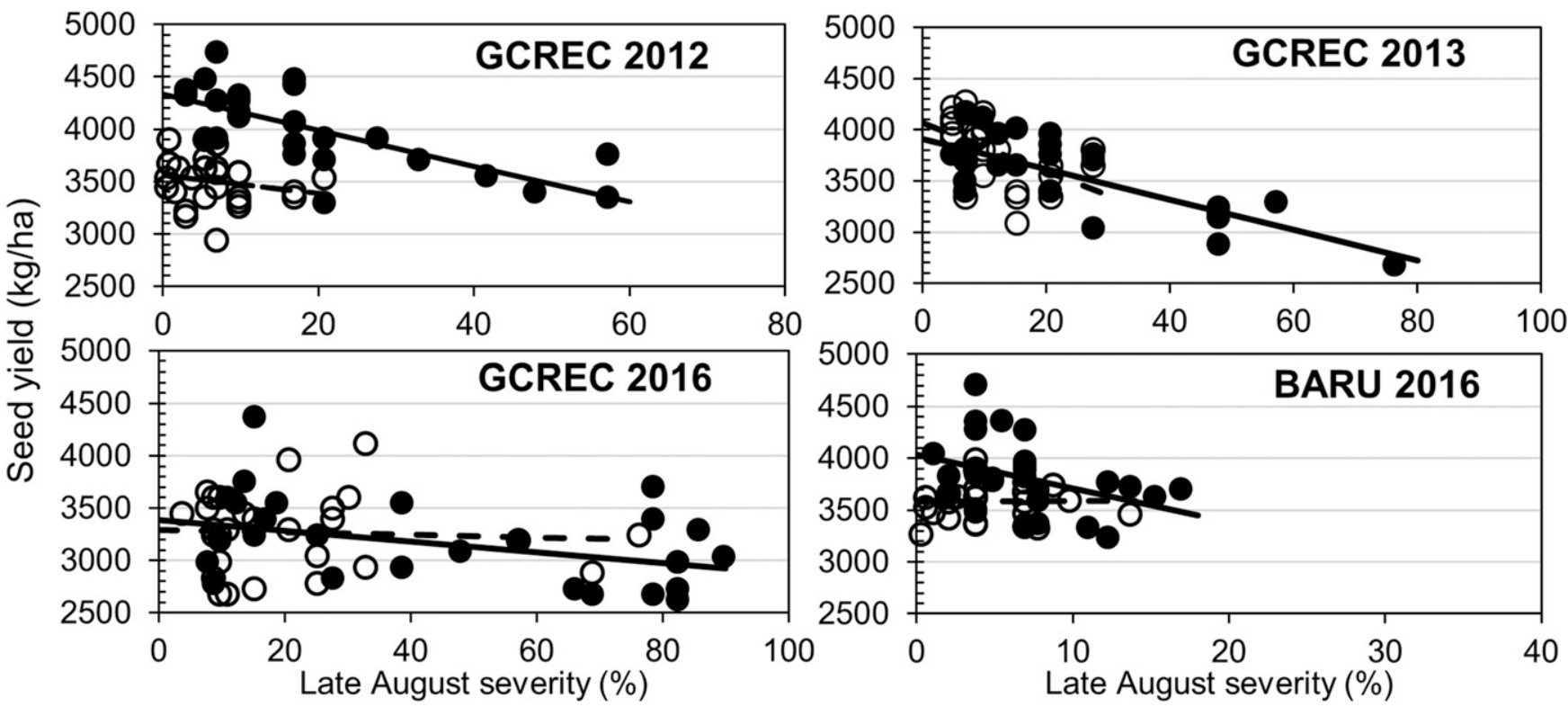

Fig. 3. Seed + lint cotton yield and disease severity (\%) levels from each of two cultivars at each of four site-years. Lines are models of yield based on defoliation and markers are actual observations. Dashed lines and open markers are for Deltapine cultivars (DP 1050 B2RF, DP 1252 B2RF, and DP 1137 B2RF in 2012, 2013, and 2016, respectively); solid lines and filled markers represent PhytoGen 499 WRF. GCREC is the Gulf Coast Research and Extension Center in Fairhope, AL, and BARU is Brewton Agricultural Research Unit, in Brewton, AL. 
is possible that some portion of observed yield increase could be attributable to the fungicide itself and not to disease reduction.

In each year of the study, a DP cultivar and PhytoGen 499 WRF were compared. Three different DP cultivars were used in the different years of the study. These DP cultivars have been compared in other tests (e.g., Hagan et al. 2013), and in general, their disease reactions and yields have been similar. Lower levels of disease and defoliation were consistently observed on these DP cultivars than on PhytoGen 499 WRF, which is consistent with previous observations (Hagan et al. 2013; Hagan et al. 2015a; Mehl et al. 2017). However, a single fungicide application to PhytoGen 499 WRF reduced target spot to a level similar to non-fungicide-treated DP cultivars. These results confirm observations that planting a less susceptible cultivar can be an efficient means of managing target spot in cotton (Hagan et al. 2018).

Despite substantial differences in disease reactions, analysis of pooled data over all treatments and site-years indicated that the two cultivars used in this study had statistically similar average yields; single degree of freedom comparisons showed that average yields of the cultivars did not differ within each treatment level. However, without a fungicide, disease severity averaged $46 \%$ and seed cotton yield averaged nearly $190 \mathrm{~kg} /$ ha lower for PhytoGen $499 \mathrm{WRF}$ than for the DP cultivars across four site-years. When late August disease severity was $<10 \%$, such as at BARU in 2016 or with three or more fungicide applications, average yields were better with PhytoGen 499 WRF than for nontreated DP cultivars.

Yield losses based on late August disease severity were calculated for PhytoGen $499 \mathrm{WRF}$, and resulting models were considered accurate for only two of the four site-years - the two site-years with abundant rainfall. For these two models, slightly less than $4 \%$ yield loss occurred with each increment of $10 \%$ target spot severity. Late August disease severity, averaged over four site-years and both cultivars, was $34 \%$ when no fungicide was applied, indicating a potential average loss of almost $13 \%$. With $3,649 \mathrm{~kg} / \mathrm{ha}$ average seed yield in this study, this loss potential is $>450 \mathrm{~kg}$ seed cotton per ha. It should be noted, however, that late August disease on PhytoGen $499 \mathrm{WRF}$ can exceed $70 \%$ when conditions for target spot are favorable, leading to $28 \%$ loss of potential yield.

Yield loss models presented here focus on the use of late August disease as the independent variable of a single point model (Campbell and Madden 1990); however, in preliminary calculations other variables including disease at earlier and later time-points were used in models. In addition, AUDPC was considered as an independent variable in yield loss models and AUDPC values incorporate disease at several time-points. Of the independent variables evaluated in models, none were better than late August disease severity relative to improving $R^{2}$, RMSE, or model significance. None of the loss models calculated herein explained substantially much more than $50 \%$ of the variability in the data; the models for the 2016 sites explained $<20 \%$ of the variability. A high incidence of bolls with hardlock was observed in 2016 in other studies near those used herein (Hagan et al. 2018), and this could have contributed to variability in yield and poor model fit.

Target spot developed rapidly through August in three of the four site-years of this study, in trials done at GCREC. At BARU in 2016, target spot of cotton caused only about $15 \%$ disease severity on

Table 4. Results from regression of disease severity against time; values for Gompertz model parameters for each cultivar in each site-year. All models had $P<$ 0.0001 .

\begin{tabular}{|c|c|c|c|c|c|c|}
\hline Cultivar & Year-site & Intercept & Slope & $R$-square & RSME $^{\mathbf{w}}$ & Predicted date of onset ${ }^{\mathrm{x}}$ \\
\hline DPy 1050 & $2012-$ GCREC $^{z}$ & -3.55 & 0.052 & 0.8988 & 0.295 & 8-Aug \\
\hline DP 1252 & 2013 - GCREC & -2.71 & 0.041 & 0.9320 & 0.229 & 29-Jul \\
\hline DP 1137 & 2016 - GCREC & -2.75 & 0.038 & 0.8933 & 0.221 & 1-Aug \\
\hline DP 1137 & 2016 - BARU & -2.32 & 0.021 & 0.7885 & 0.179 & 7-Aug \\
\hline \multirow[t]{4}{*}{ PhytoGen 499} & 2012 - GCREC & -4.18 & 0.081 & 0.9853 & 0.168 & 2-Aug \\
\hline & 2013 - GCREC & -2.85 & 0.055 & 0.9582 & 0.239 & 24-Jul \\
\hline & 2016 - GCREC & -3.99 & 0.088 & 0.9286 & 0.408 & 28-Jul \\
\hline & 2016 - BARU & -2.76 & 0.034 & 0.8348 & 0.250 & 5-Aug \\
\hline
\end{tabular}

${ }^{\mathrm{w}}$ RSME is "Root Mean Square Error" and reflects differences between observed values and predicted values.

$\mathrm{x}$ Disease severity at $1 \%$ was used for onset.

y $\mathrm{DP}=$ Deltapine.

${ }^{\mathrm{z}}$ Site acronyms are: GCREC $=$ Gulf Coast Research and Extension Center in Fairhope, AL; BARU = Brewton Agricultural Research Unit in Brewton, AL
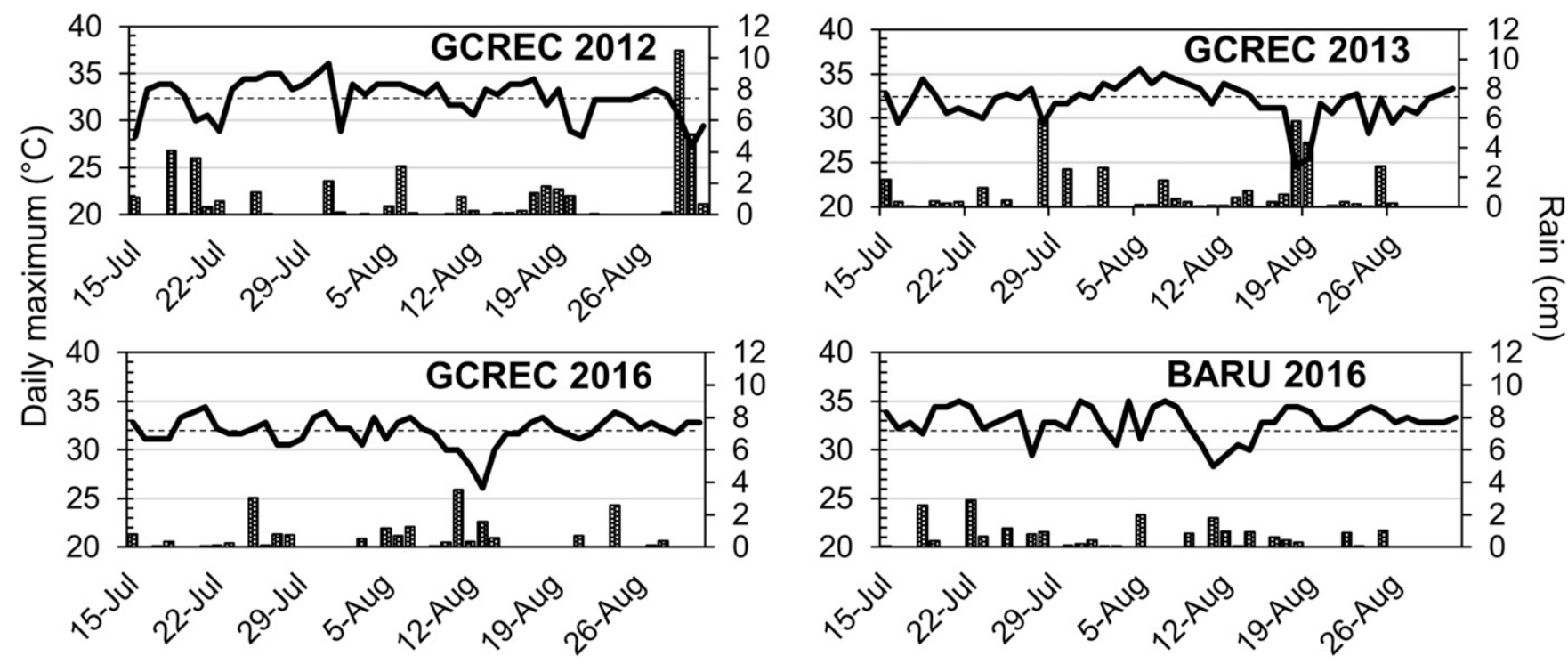

Fig. 4. Daily maximum temperature (solid line) and rainfall (bars) from 15 July to 31 Aug for each of four site-years. Horizontal dashed line clarifies $32^{\circ} \mathrm{C}$. GCREC is the Gulf Coast Research and Extension Center in Fairhope, AL, and BARU is Brewton Agricultural Research Unit, in Brewton, AL. 
PhytoGen 499 WRF, the more susceptible cultivar. BARU is about $103 \mathrm{~km}$ northeast of GCREC. Lower disease pressure at BARU could be due to the location (i.e., different soil and surrounding ecosystem). However, relatively low rainfall has been associated with reduced target spot in a previous study (Hagan et al. 2017); in addition, the frequency of warmer days at BARU during target spot development in August concurs with growth chamber observations that temperatures $>28^{\circ} \mathrm{C}$ delay symptom development on $C$. cassiicola-inoculated plants (Sharma 2017).

The Gompertz model provided slightly better prediction of target spot development on cotton than did the logistic model. This result agrees with previous observations by Berger (1981), who had shown that the Gompertz model more accurately reflected 113 plant disease epidemics than did the logistic model. Disease develops more rapidly in early stages than in late stages of an epidemic according to the Gompertz model. Because of this, as Berger (1981) noted, the time at which a particular level of disease is reached would be earlier when an epidemic progressed according to the Gompertz compared with the logistic model. This suggests that disease management, as with a fungicide application, would be most effective when applied early in epidemic development. Gompertz model calculations confirmed our observations that target spot typically starts to develop in late July, and this is likely a critical time to apply fungicide for managing this disease. Knowing that target spot develops according to the Gompertz model, and noting how model parameter values differed in varying conditions, can contribute to forecasting and disease modeling. For example, these models show that disease onset was delayed 2 to 6 days on the DP cultivars compared with the more susceptible PhytoGen 499 WRF. In addition, the apparent infection rate for each cultivar was lower at BARU 2016, the site-year with the least favorable weather for target spot development.

Disease onset, as calculated using the Gompertz model and observed as lesions in the lower canopy, occurred in late July to early August. This is generally when the cotton canopy closed over the row in our production system. Canopy closure appears to be critical to target spot onset and disease development, presumably due to longer periods of leaf wetness and high humidity in the dense canopy (Kora et al. 2005). Knowledge about the timing of disease onset can contribute to efficient scouting for target spot and fungicide application timing.

In rating disease in the field, we used a "leaf spot" scale that encompassed both lesion densities and defoliation (Chiteka et al. 1988). Low scores on this scale $(2,3$, and 4$)$ reflect increasing lesion densities, while the high scores $(6,7,8$, and 9$)$ focus on increasing defoliation. If a fungicide application made at the time of disease onset ( $1 \%$ severity across the plot) is most efficient for disease management, this would be done prior to conspicuous defoliation or when disease is rated at 2 or 3 . In the absence of an accurate forecast system for target spot, use of this disease scale to assess target spot occurrence can be readily used by growers or consultants when determining the need for a fungicide application.

\section{Literature Cited}

Bashi, E., Sachs, Y., and Rotem, J. 1983. Relationships between disease and yield in cotton fields affected by Alternaria macrospora. Phytoparasitica 11:89-98.

Berger, R. D. 1981. Comparison of the Gompertz and logistic equations to describe plant disease progress. Phytopathology 71:716-719.

Blazquez, C. H. 1967. Corynespora leaf spot of cucumber. Florida State Hortic. Soc. Florida Agric. Exp. Stn. J. Ser. No. 2858. Pages 177-182.

Butler, S., Young-Kelly, H., Raper, T., Cochran, A., and Jordan, J. 2016. First report of target spot caused by Corynespora cassiicola on cotton in Tennessee. Plant Dis. 100:535.

Campbell, C. L., and Madden, L. V. 1990. Plant Disease Epidemiology. WileyInterscience Pub., NY.
Chiteka, Z. A., Gorbet, D. W., Knauft, D. A., Shokes, F. M., and Kucharek, T. A 1988. Components of resistance to late leaf spot in peanut. II. Correlations among components and their significance in breeding for resistance. Peanut Sci. 15:76-81.

Conner, K., Hagan, A. K., and Zhang, L. 2013. First Report of Corynespora cassiicola-incited target spot on cotton in Alabama. Plant Dis. 97:1379.

Fernando, T. H. P. S., Jayasinghe, C. K., Wijesundera, R. L. C., and Siriwardana, D. 2010. Screening of fungicides against Corynespora leaf fall disease of rubber under nursery conditions. J. Plant Dis. Prot. 117:117-121.

Fulmer, A. M., Walls, J. T., Dutta, B., Parkunan, V., Brock, J., and Kemerait, R. C., Jr. 2012. First report of target spot caused by Corynespora cassiicola on cotton in Georgia. Plant Dis. 96:1066.

Galbieri, R., Araugo, D. C. E. B., Kobayasti, L., Girotto, L., Matos, J. N., Marangoni, M. S., Almeida, W. P., and Mehta, Y. R. 2014. Corynespora leaf blight of cotton in Brazil and its management. Am. J. Plant Sci. 5:3805-3811.

Hagan, A. K., Bowen, K. L., Burch, K., and Miller, H. B. 2015a. Fungicide inputs and control of target spot on seven cotton varieties in southwest Alabama, 2014 Plant Dis. Manage. Rep. 9:FC136.

Hagan, A. K., Bowen, K. L., Burch, K., Pegues, M., Jones, J., and Scott, S. 2017 Impact of planting date and seeding rate on the severity of target spot in cotton. Beltwide Cotton Conferences Proc. 2017: 224-232.

Hagan, A. K., Bowen, K. L., Miller, B., and Nichols, R. L. 2018. Target spotincited defoliation and yields of selected cotton cultivars as influenced by fungicide inputs. Plant Health Prog. 19:156-162.

Hagan, A. K., Bowen, K. L., Pegues, M., and Jones, J. 2015b. Relationship between target spot intensity and seed cotton yield. Phytopathology 105:S2.4.

Hagan, A. K., Campbell, H. L., Bowen, K. L., Pegues, M., and Jones, J. 2013. Reaction of mid- and full season flex cotton varieties to target spot in Alabama, 2012. Plant Dis. Manage. Rep. 7:FC006.

Jayasinghe, C. K. 2000. Corynespora leaf fall: The most challenging rubber disease in Asian and African continents. Bull. Rubber Res. Inst. Sri Lanka 42:56-64

Kanungo, M., and Joshi, J. 2014. Impact of pyraclostrobin (F-500) on crop plants. Plant Sci. Today 1:174-178.

Koenning, S. R., Creswell, T. C., Dunphy, E. J., Sikora, E. J., and Mueller, J. D. 2006. Increased occurrence of target spot of soybean caused by Corynespora cassiicola in the Southeastern United States. Plant Dis. 90:974.

Kora, C., McDonald, M. R., and Boland, G. J. 2005. Lateral clipping of canopy influences the microclimate and development of Sclerotinia sclerotiorum in carrots. Plant Dis. 89:549-557.

Li, Y., Culbreath, A. K., Chen, C. Y., Knapp, S. J., Holbrook, C. C., and Guo, B. 2012. Variability in field response of peanut genotypes from the U.S. and China to tomato spotted wilt virus and leaf spots. Peanut Sci. 39:30-37.

Madden, L. V., Hughes, G., and van den Bosch, F. 2007. The Study of Plant Disease Epidemics. APS Press, St. Paul, MN.

Mehl, H., Dufault, N., Mulvanney, M., Hagan, A. K., Kelly, H., Kemerait, R. Price, P., Allen, T., Lawrence, K., and Nichols, R. 2017. Multi-year regional evaluation of one and two applications of registered and experimental fungicides for the management of target spot on two cotton varieties. Beltwide Cotton Conferences Proc. 2017: 222-223.

NASS (National Agricultural Statistics Service). 2017. Crop production. Released May 10, 2017.

Pernezny, K., Stoffella, P., Collins, J., Carroll, A., and Beaney, A. 2002. Control of target spot of tomato with fungicides, systemic acquired resistance activators, and a biocontrol agent. Plant Prot. Sci. 38:81-88.

Price, P., Singh, R., and Fromme, D. 2015. First report of target spot caused by Corynespora cassiicola in Louisiana cotton. Plant Health Prog. 16:223-224.

Reed, T., Jacobson, A., Smith, R., Freeman, B., Hagan, A. K., Tredaway, J. A., and Monks, D. 2017. Cotton Insect, Disease, Nematode, and Weed Control Recommendations for 2017. AL Coop. Ext. Sys. 2017:IPM-0415.

Rodriguez, R., and Melendez, P. L. 1984. Chemical control of cowpea powdery mildew and foliar spots. J. Agric. Univ. P R. 48:445-455

Schultz, J. 2017. Target spot epidemic in the North Delta: 2016, Observations and key learnings. Page 242 in: Beltwide Cotton Conferences Proc. 2017.

Shaner, G., and Finney, R. E. 1977. The effect of nitrogen fertilization on the expression of slow-mildewing resistance in wheat. Phytopathology 67:1051-1056.

Sharma, N. 2017. Epidemiology of target spot of cotton and tomato. M.S. Thesis. Auburn University.

Wei, Y.-X., Zhang, H., Pu, J.-J., and Liu, X.-M. 2014. First report of target spot caused by Corynespora cassiicola in China. Plant Dis. 98:1006.

Woodward, J. E., Dodds, D. M., Main, C. L., Barber, L. T., Boman, R. K., Whitaker, J. R., Edmisten, K. L., Banks, J. C., Buehring, N. W., and Allen, T. W. 2016. Evaluation of foliar applications of strobilurin fungicides in cotton across the Southern United States. J. Cotton Sci. 20:116-124. 